\title{
FAKTOR-FAKTOR YANG BERHUBUNGAN DENGAN KUALITAS MIKROBIOLOGIS PRODUK INDUSTRI RUMAH TANGGA PANGAN
}

\author{
Sri Mulyati*, Herlinawati**
}

\begin{abstract}
ABSTRAK
Pangan penyebab Kejadian Luar Biasa (KLB) keracunan pangan yang paling banyak adalah dari masakan rumah tangga. Masakan rumah tangga dapat dikategorikan pada pangan produksi Industri Rumah Tangga Pangan (IRTP). Keracunan makanan biasanya erat kaitannya dengan sanitasi dan hygienitas pangan, untuk itu perlu dilakukan pengawasan kualitas mikrobiologis makanan melalui uji colliform. Penelitian ini bertujuan untuk mengetahui hubungan antara faktor tempat, peralatan, personal hygiene, pengetahuan serta hygiene dan sanitasi makanan dengan kualitas mikrobiologis makanan minuman produk IRTP di Kabupaten Tegal. Jenis penelitian ini adalah observasional dengan metode survei dan pendekatan cross sectional. Populasinya adalah 70 buah IRTP di Kabupaten Tegal. Pengambilan sampel melalui metode Proportional Random Sampling. Pengumpulan data dengan menggunakan wawancara dan observasi. Analisis data menggunakan chi square. Hasil penelitian menunjukkan bahwa ada hubungan antara tempat $(p=0,011)$, personal hygiene $(p=0,004)$, pengetahuan $(\mathrm{p}=0,022)$, dan hygiene dan sanitasi makanan $(p=0,019)$, dengan kualitas mikrobiologis makanan.
\end{abstract}

Kata kunci : Kualitas mikrobiologis makanan

\section{ABSTRACT}

Food causes Extraordinary Events (KLB) food poisoning is at most of the home cooking. Household cooking can also be categorized on the food production industry Household Food Security (IRTP). Food poisoning is usually closely related to sanitation and food hygienitas, for it is necessary to control the microbiological quality of food through colliform test. This study aimed to determine the relationship between the factor space, equipment, personal hygiene, hygiene and sanitation knowledge and food with microbiological quality food and beverage products IRTP in Tegal regency. The study was observational methods and a cross sectional survey. Its population is 70 pieces IRTP in Tegal regency. Sampling through with proportional random sampling. Collecting data using interviews and observasions. Data analysis using chi square. The results showed that there is a relationship between the place $(p=0.011)$, personal hygiene $(p=0.004)$, knowledge $(p=0.022)$, and hygiene and sanitation of food $(\mathrm{p}=0.019)$ the microbiological quality of food.

Keywords : Quality of food microbiological

\footnotetext{
* Alumni PSKM STIKes Cirebon Lulus Tahun 2013

** Staf Pengajar Program Studi S1 Kesehatan Masyarakat STIKes Cirebon
} 


\section{PENDAHULUAN}

Berbagai upaya dilakukan pemerintah guna memenuhi kebutuhan makanan yang aman, bermutu, bergizi dan tersedia secara cukup. Melalui keamanan pangan pemerintah berupaya menjaga kualitas makanan sehingga makanan dapat berfungsi sebagaimana mestinya, aman karena tidak mengandung kontaminasi kuman-kuman penyakit serta tidak mengandung zatzat toksin atau racun yang dapat membahayakan kelangsungan hidup seseorang. ${ }^{1}$

Lebih dari 90\% terjadinya penyakit yang diakibatkan makanan (foodborne diseases) disebabkan oleh kontaminasi mikroba. Foodborne diseases lazim dikenal dengan istilah keracunan makanan. Kasus keracunan makanan ini sangat erat kaitannya dengan sanitasi dan higinitas makanan dan minuman. ${ }^{2}$ Sebagian dari mikroba tidak berbahaya, tetapi banyak juga yang dapat menyebabkan infeksi pada manusia dan hewan. Mikroba dapat berkembang biak dan menginfeksi jaringan tubuh dalam keadaan tertentu dan dapat menular, baik antara manusia dan manusia, hewan dengan hewan ataupun menular dari hewan ke manusia atau sebaliknya, secara langsung atau melalui pangan. Makanan menjadi beracun karena telah tercemar oleh mikroba tertentu dan mikroba tersebut menghasilkan racun yang cukup banyak yang dapat membahayakan konsumen. ${ }^{3}$

Ratusan juta manusia menderita penyakit menular dan tidak menular karena pangan yang tercemar. Yang mencengangkan, kebanyakan dari kasus tersebut berasal dari produk olahan rumah tangga. Menurut Dr Ir Roy Sparingga, M.App,Sc, Deputi Keamanan Pangan dan Bahan Berbahaya BPOM mengatakan dari data kejadian luar biasa (KLB) untuk kasus keracunan makanan, maka yang terbanyak adalah berasal dari masakan rumah tangga. Agen dugaan penyebab KLB keracunan makanan paling banyak disebabkan oleh mikroba yaitu sebesar $21 \%$, sedangkan bahan kimia $13 \%$ dan sisanya tidak ada sampel. ${ }^{4}$

Keracunan makanan akibat cemaran mikroba dikarenakan masyarakat umumnya belum mengetahui cara pengolahan pangan yang baik, oleh karena itu perlu adanya pengawasan mutu untuk mengetahui kualitas mikrobiologis makanan.. Salah satu cara mengetahui kualitas mikrobiologis adalah dengan melakukan uji terhadap jumlah coliform karena coliform adalah salah satu indikator adanya pencemaran yang berasal dari kotoran manusia atau hewan dan hal ini dianggap identik dengan dengan adanya bakteri patogen. Adanya coliform pada makanan berarti makanan tersebut tidak layak dikonsumsi karena dimungkinkan mengandung bakteri patogen sehingga dapat menimbulkan gangguan kesehatan. ${ }^{5}$

Data Dinas Kesehatan Kabupaten Tegal diperoleh bahwa jumlah Industri Rumah Tangga Pangan (IRTP) di Kabupaten Tegal dari tahun 2010 sampai 2012 mengalami peningkatan sebesar 64\% (45 industri menjadi 70 industri). Namun perkembangan yang pesat tak diikuti dengan upaya penerapan keamanan pangan oleh para pengusahanya terbukti kebanyakan IRTP belum menerapkan Cara Produksi Pangan yang Baik (CPPB) dengan tepat sehingga sebagaimana industri kecil pada umumnya maka IRTP pun terbelit aneka permasalahan baik teknis maupun manajerial. Hal ini terlihat dari IRTP yang telah terdaftar tersebut diketahui bahwa $25 \%$ hasil sampel produknya tidak memenuhi syarat secara mikrobiologis. ${ }^{6}$ Pertumbuhan mikroba pada makanan dapat terjadi akibat sanitasi dan higienitas pemasakan yang rendah. Persyaratan mikrobiologis pada makanan dan minuman merujuk pada Keputusan Direktur Jenderal Pengawasan Obat dan makanan No : 03726/B/SK/VII/89 tentang Batas maksimum cemaran mikroba makanan dan pada persyaratan Standar Nasional Indonesia (SNI). ${ }^{7}$

Menurut World Health Organization (WHO), kualitas mikrobiologis makanan dipengaruhi oleh beberapa faktor. Faktor-faktor yang berhubungan dengan kualitas mikrobiologis makanan tersebut antara lain adalah faktor fisik (alat dan tempat), faktor personal (penjamah makanan) serta faktor operasional/penanganan makanan. ${ }^{8}$ Tujuan dalam 
penelitian ini adalah untuk mengetahui faktor-faktor yang berhubungan dengan kualitas mikrobiologis produk Industri Rumah Tangga Pangan di Kabupaten Tegal Tahun 2013.

\section{METODE PENELITIAN}

Penelitian ini merupakan jenis penelitian observasional. Metode yang digunakan yaitu survey analitik. ${ }^{9}$ Pendekatan penelitian ini adalah seksional silang (cross sectional). Variabel Bebas meliputi faktor tempat produksi, faktor peralatan produksi, faktor penjamah makanan, pengetahuan pekerja dan faktor operasional atau penanganan pangan. Variabel terikat terdiri dari kualitas mikrobiologis makanan.

Populasi pada penelitian ini adalah jumlah Industri Rumah Tangga Pangan yang terdaftar di Dinas Kesehatan Kabupaten Tegal. Data IRTP di Kabupaten Tegal pada tahun 2010 sampai dengan 2012 yang tersebar di 18 kecamatan diperoleh data sebanyak 70 industri. Besar sampel yang didapatkan sebesar 36 industri, teknik pengambilan sampel pada penelitian ini adalah dengan cara Proportional Random Sampling. ${ }^{9}$ Data yang diperoleh secara langsung melalui pemeriksaan laboratorium, observasi dan wawancara. Data dianalisis dengan menggunakan uji Chi-square, untuk melihat hasil kemaknaan perhitungan statistik digunakan batas kemaknaan 0,05 .

\section{HASIL PENELITIAN}

\section{Kualitas Mikrobiologis Makanan dan Minuman Produk Industri Rumah Tangga}

Hasil Penelitian menunjukkan bahwa dari 36 industri yang diteliti terdapat 13 sampel makanan (36\%) yang memiliki kualitas mikrobiologis yang tidak memenuhi syarat.

\section{Tempat Produksi}

Hasil penelitian ini menunjukkan bahwa dari 36 industri yang diteliti, lebih dari sebagian $(52,8 \%)$ industri mempunyai kategori tempat produksi yang kurang baik.

\section{Peralatan Untuk Proses Pengolahan}

Hasil penelitian ini menunjukan bahwa dari 36 industri yang diteliti terdapat 15 industri $(41,7 \%)$ yang memiliki peralatan untuk proses pengolahan yang kurang baik.

\section{Personal Hygiene}

Hasil penelitian ini menunjukan bahwa dari 36 industri terdapat 15 industri $(41,7 \%)$ memiliki personal hygiene yang kurang baik.

\section{Pengetahuan}

Hasil penelitian menunjukkan bahwa dari 36 industri terdapat 20 responden $(55,6 \%)$ yang memiliki pengetahuan kurang baik.

\section{Hygiene dan Sanitasi Makanan}

Hasil penelitian menunjukkan bahwa dari 36 industri yang diteliti terdapat 17 industri $(47,2 \%)$ memiliki hygiene dan sanitasi makanan yang kurang baik. 


\section{Hubungan antara Tempat Produksi dengan Kualitas Mikrobiologis Makanan Produk IRTP}

Tabel 1 Hasil Analisis Bivariat Antara Tempat Produksi dengan Kualitas Mikrobiologis Makanan Produk IRTP

\begin{tabular}{|c|c|c|c|c|c|c|c|c|}
\hline \multirow{3}{*}{ No. } & \multirow{3}{*}{$\begin{array}{l}\text { Tempat } \\
\text { Produksi }\end{array}$} & \multicolumn{4}{|c|}{ Kualitas Mikrobiologis } & \multirow{2}{*}{\multicolumn{2}{|c|}{ Jumlah }} & \multirow{3}{*}{ Pvalue } \\
\hline & & \multicolumn{2}{|c|}{$\begin{array}{c}\text { Tidak Memenuhi } \\
\text { Syarat }\end{array}$} & \multicolumn{2}{|c|}{ Memenuhi Syarat } & & & \\
\hline & & $\mathrm{n}$ & $\%$ & $\mathrm{n}$ & $\%$ & $\mathrm{n}$ & $\%$ & \\
\hline 1. & Kurang baik & 11 & 57,9 & 8 & 42,1 & 19 & 100 & \\
\hline \multirow[t]{2}{*}{2.} & Baik & 2 & 11,8 & 15 & 88,2 & 17 & 100 & 0,011 \\
\hline & Jumlah & 13 & 36,1 & 23 & 63,9 & 36 & 100 & \\
\hline
\end{tabular}

Hasil uji chi-square menunjukkan bahwa nilai $p$ adalah 0,011 atau lebih kecil dari 0,05 berarti ada hubungan antara tempat produksi dengan kualitas mikrobiologis makanan.

\section{Hubungan antara Peralatan Produksi dengan Kualitas Mikrobiologis Industri Rumah Tangga Pangan}

Tabel 2 Hasil Analisis Bivariat Antara Peralatan dengan Kualitas Mikrobiologis Makanan Produk IRTP

\begin{tabular}{|c|c|c|c|c|c|c|c|c|}
\hline \multirow{3}{*}{ No. } & \multirow{3}{*}{$\begin{array}{l}\text { Peralatan } \\
\text { Produksi }\end{array}$} & \multicolumn{4}{|c|}{ Kualitas Mikrobiologis } & \multirow{2}{*}{\multicolumn{2}{|c|}{ Jumlah }} & \multirow{3}{*}{ Pvalue } \\
\hline & & \multicolumn{2}{|c|}{$\begin{array}{c}\text { Tidak } \\
\text { Memenuhi } \\
\text { Syarat }\end{array}$} & \multicolumn{2}{|c|}{$\begin{array}{c}\text { Memenuhi } \\
\text { Syarat }\end{array}$} & & & \\
\hline & & $\mathrm{n}$ & $\%$ & $\mathrm{n}$ & $\%$ & $\mathrm{~N}$ & $\%$ & \\
\hline 1. & Kurang baik & 8 & 53,3 & 7 & 46,7 & 15 & 100 & \\
\hline \multirow[t]{2}{*}{2.} & Baik & 5 & 23,8 & 16 & 76,2 & 21 & 100 & 0,143 \\
\hline & Jumlah & 13 & 36,1 & 23 & 63,9 & 36 & 100 & \\
\hline
\end{tabular}

Hasil dari uji chi-square menunjukkan bahwa nilai $p$ adalah $0,143(p>0,05)$ berarti tidak ada hubungan antara peralatan produksi dengan kualitas mikrobiologis makanan.

\section{Hubungan antara Personal Hygiene dengan Kualitas Mikrobiologis Makanan}

Tabel 3 Hasil Analisis Bivariat Antara Personal Hygiene dengan Kualitas Mikrobiologis Makanan Produk IRTP

\begin{tabular}{|c|c|c|c|c|c|c|c|c|}
\hline \multirow{3}{*}{ No. } & \multirow{3}{*}{$\begin{array}{l}\text { Personal } \\
\text { Hygiene }\end{array}$} & \multicolumn{4}{|c|}{ Kualitas Mikrobiologis } & \multirow{2}{*}{\multicolumn{2}{|c|}{ Jumlah }} & \multirow[b]{2}{*}{ Pvalue } \\
\hline & & \multicolumn{2}{|c|}{$\begin{array}{c}\text { Tidak } \\
\text { Memenuhi } \\
\text { Syarat }\end{array}$} & \multicolumn{2}{|c|}{$\begin{array}{l}\text { Memenuhi } \\
\text { Syarat }\end{array}$} & & & \\
\hline & & $\mathrm{n}$ & $\%$ & $\mathrm{n}$ & $\%$ & $\mathrm{n}$ & $\%$ & \multirow{4}{*}{0,004} \\
\hline 1. & Kurang baik & 10 & 66,7 & 5 & 33,3 & 15 & 100 & \\
\hline \multirow[t]{2}{*}{2.} & Baik & 3 & 14,3 & 18 & 85,7 & 21 & 100 & \\
\hline & Jumlah & 13 & 36,1 & 23 & 63,9 & 36 & 100 & \\
\hline
\end{tabular}


Hasil uji chi-square menunjukkan bahwa nilai $p$ adalah 0,004 atau lebih kecil dari 0,05 berarti ada hubungan yang bermakna antara personal hygiene dengan kualitas mikrobiologis makanan.

\section{Hasil Analisis Bivariat Antara Pengetahuan dengan Kualitas Mikrobiologis Makanan Produk Industri Rumah Tangga Pangan}

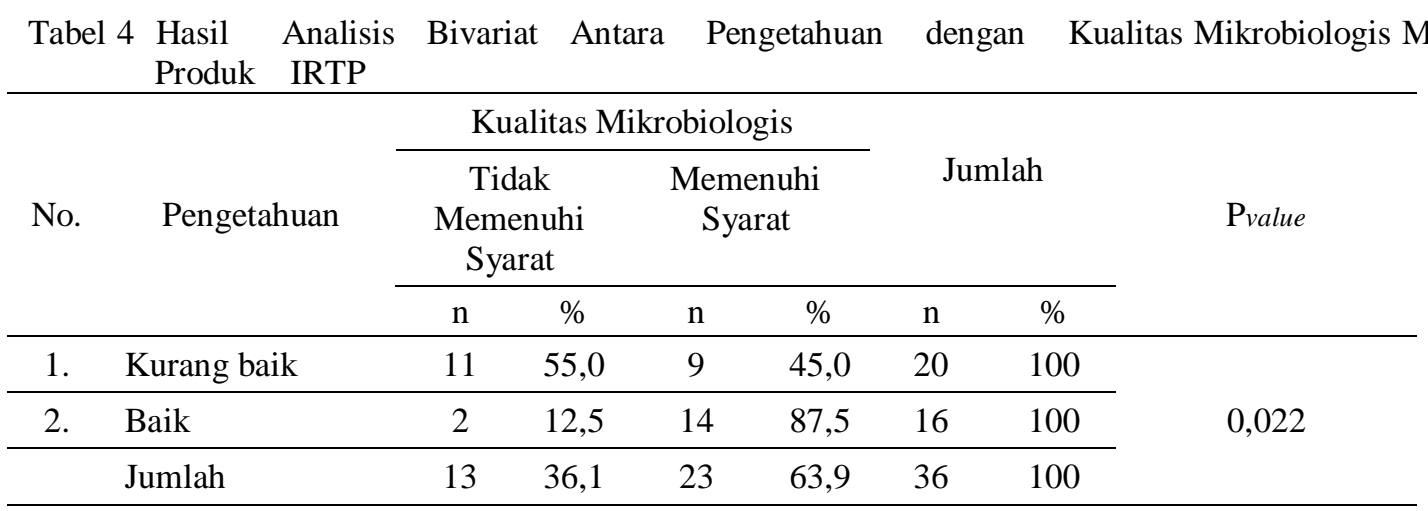

Uji Chi-Square menunjukkan bahwa terdapat hubungan yang bermakna antara pengetahuan dengan kualitas mikrobiologis makanan karena didapatkan nilai $p$ sebesar 0,022 $(p<0,05)$.

\section{Hubungan Hygiene dan Sanitasi Makanan dengan Kualitas Mikrobiologis Makanan Industri Rumah Tangga Pangan}

Tabel 5 Hasil Analisis Bivariat Antara Hygiene dan Sanitasi Makanan dengan Kualitas Mikrobiologis Makanan Produk IRTP

\begin{tabular}{|c|c|c|c|c|c|c|c|c|}
\hline \multirow{3}{*}{ No. } & \multirow{3}{*}{$\begin{array}{c}\text { Hygiene dan } \\
\text { Sanitasi Makanan }\end{array}$} & \multicolumn{4}{|c|}{ Kualitas Mikrobiologis } & & & \multirow{3}{*}{ Pvalue } \\
\hline & & \multicolumn{2}{|c|}{$\begin{array}{c}\text { Tidak } \\
\text { Memenuhi } \\
\text { Syarat }\end{array}$} & \multicolumn{2}{|c|}{$\begin{array}{l}\text { Memenuhi } \\
\text { Syarat }\end{array}$} & \multicolumn{2}{|c|}{ Jumlah } & \\
\hline & & $\mathrm{n}$ & $\%$ & $\mathrm{n}$ & $\%$ & $\mathrm{n}$ & $\%$ & \\
\hline 1. & Kurang baik & 10 & 58,8 & 7 & 41,2 & 17 & 100 & \multirow{3}{*}{0,019} \\
\hline \multirow[t]{2}{*}{2.} & Baik & 3 & 15,8 & 16 & 84,2 & 19 & 100 & \\
\hline & Jumlah & 13 & 36,1 & 23 & 63,9 & 36 & 100 & \\
\hline
\end{tabular}

Hasil uji chi-square menunjukkan bahwa terdapat hubungan antara hygiene dan sanitasi makanan dengan kualitas mikrobiologis makanan karena diperoleh $p<0,05$ yaitu 0,019 .

\section{PEMBAHASAN}

\section{Hubungan Tempat Produksi dengan Kualitas Mikrobiologis Makanan Produk Industri Rumah Tangga Pangan}

Hasil penelitian menunjukkan adanya hubungan antara tempat produksi dengan kualitas mikrobiologis makanan produk industri rumah tangga pangan di kabupaten tegal tahun 2013. Hasil penelitian ini sesuai dengan dengan penelitian yang dilakukan oleh Pracoyo yang meneliti tentang Analisis Mikrobiologis Beberapa Jajanan di DKI Jakarta pada tahun 2006 yang menyatakan bahwa faktor tempat merupakan faktor yang dapat mempengaruhi kualitas 
mikrobiologis makanan dengan nilai $p=0,025 \cdot{ }^{10}$ Tempat produksi yang tidak dilengkapi fasilitas sanitasi yang memadai akan menimbulkan berbagai hal yang tak diinginkan dan secara otomatis menjadi ancaman yang serius terhadap keamanan pangan.

\section{Hubungan Peralatan Produksi dengan Kualitas Mikrobiologis Industri Rumah Tangga Pangan}

Hasil penelitian menunjukkan tidak adanya hubungan, antara peralatan produksi dengan kualitas mikrobiologis makanan produk Industri Rumah Tangga Pangan di Kabupaten Tegal Tahun 2013. Hasil penelitian ini sesuai dengan hasil penelitian yang telah dilakukan oleh Siti Nuraeny yang meneliti tentang Analisis Kualitas Mikrobiologis produk Usaha Kecil Menengah (UKM) di Kabupaten Tegal Tahun 2009 yang menyatakan bahwa tidak ada hubungan antara peralatan produksi dengan kualitas mikrobiologis makanan, dimana nilai $p=$ $0,201 .^{11}$

Kontaminasi peralatan pada makanan dapat dipengaruhi oleh permukaan alat yang kontak langsung dengan pangan. Permukaan peralatan masak ada yang tidak halus, bercelah, bahkan mengelupas dikarenakan cacat atau rusak namun tetap dipakai dalam proses produksi.

\section{Hubungan Personal Hygiene dengan Kualitas Mikrobiologis Makanan}

Hasil penelitian menunjukkan bahwa terdapat hubungan antara personal hygiene dengan kualitas mikrobiologis makanan. Hasil penelitian ini sejalan dengan hasil penelitian yang telah dilakukan oleh Siti Nuraeny yang meneliti tentang Analisis Kualitas Mikrobiologis produk Usaha Kecil Menengah (UKM) di Kabupaten Tegal Tahun 2009 yang menyatakan bahwa terdapat hubungan antara personal hygiene dengan kualitas mikrobiologis makanan dengan nilai $p=0,020 .{ }^{11}$ Personal hygiene merupakan salah satu faktor pendukung kualitas mikrobiologis makanan.

\section{Hubungan Pengetahuan dengan Kualitas Mikrobiologis Makanan}

Hasil penelitian menunjukkan bahwa terdapat hubungan antara pengetahuan dengan kualitas mikrobiologis makanan produk Industri Rumah Tangga Pangan di Kabupaten Tegal. Hasil penelitian ini sejalan dengan penelitian Yogo Widodo yang meneliti tentang Hubungan Tingkat Pengetahuan Penjamah Makanan mengenai Hygiene dan Sanitasi Makanan dengan Kualitas Bakteriologis Makanan pada Rumah Makan di Kota Magelang pada Tahun 2004. ${ }^{12}$ Pengetahuan merupakan faktor pendukung kualitas mikrobiologis makanan.

\section{Hubungan Antara Hygiene dan Sanitasi Makanan dengan Kualitas Mikrobiologis Makanan}

Hasil penelitian menunjukkan bahwa terdapat hubungan antara hygiene dan sanitasi makanan dengan kualitas mikrobiologis makanan. Hasil penelitian ini sesuai dengan penelitian Budi Hartono yang meneliti tentang Pemantauan Kualitas Makanan Ketoprak dan Gado-Gado di Lingkungan Kampus UI Depok melalui Pemeriksaan Bakteriologis pada tahun 2003 yang menyatakan bahwa hygiene dan sanitasi makanan berhubungan dengan kualitas mikrobiologis makanan. ${ }^{13}$

Kebersihan pada setiap tahap proses pengolahan yang dimulai dari persiapan dan penyediaan bahan baku, pemakaian air bersih, tahapan pengolahan dan pasca pengolahan makanan merupakan langkah-langkah penting untuk menghindari terjadinya infeksi dan intoksikasi. 


\section{SIMPULAN}

1. Ada hubungan antara tempat produksi Industri Rumah Tangga Pangan dengan kualitas mikrobiologis makanan.

2. Tidak ada hubungan antara peralatan produksi Industri Rumah Tangga Pangan dengan kualitas mikrobiologis makanan.

3. Ada hubungan antara personal hygiene dengan kualitas mikrobiologis makanan.

4. Ada hubungan antara pengetahuan dengan kualitas mikrobiologis makanan.

5. Ada hubungan antara hygiene dan sanitasi makanan dengan kualitas mikrobiologis makanan.

\section{SARAN}

1. Bagi Industri Rumah Tangga Pangan (IRTP) :

Penanggungjawab/pemilik IRTP agar memperbaiki tempat produksi dan wajib mengajarkan kepada setiap karyawannya tentang penyuluhan atau pelatihan Cara Produksi yang Baik (CPPB) yang telah didapat.

2. Bagi Instansi Dinas Kesehatan

Dinas Kesehatan Kabupaten Tegal agar melakukan pembinaan dan pengawasan IRTP yang telah terdaftar dengan lebih terfokus yang dilakukan selama dua kali setahun dan yang belum terdaftar agar mendaftarkan produk makanan/minuman yang diproduksinya.

\section{DAFTAR PUSTAKA}

1. Kertasapoetra, G. dan H. Marsetyo. Ilmu gizi (korelasi gizi, kesehatan dan poduktifitas Kerja), Jakarta: Rineka Cipta; 2003

2. Balai Besar POM, TOT Distric food inspector. Semarang; 2005

3. Jacob, M. Safe food handling. England: Macmiland Clays; 1989

4. Anonim, Health news. [di akses tanggal 31 Oktober 2013]. Diunduh dari : http//www.detik.com

5. Riski M. Mulia. Kesehatan lingkungan. Jakarta: Graha Ilmu; 2005

6. UPTD Laboratorium Kesehatan Kabupaten Tegal, Laporan hasil pemeriksaan bakteriologis makanan. Tegal. UPTD Labkes Kabupaten Tegal; 2010

7. Departemen Kesehatan RI. Petunjuk pemeriksaan mikrobiologi makanan dan minuman. Jakarta: Departemen Kesehatan RI; 1991

8. Adams M, Motarjemi Y. Dasar-dasar keamanan makanan untuk petugas kesehatan. Jakarta: Penerbit Buku Kedokteran EGC;2004

9. Notoatmodjo, Soekidjo. Metodologi penelitian kesehatan. Jakarta: PT. Rineka Cipta;2003

10. Pracoyo, Analisis mikrobiologis beberapa jajanan di DKI Jakarta tahun 2006 Jakarta: Seri Kesehatan;2006 (Tidak dipublikasikan)

11. Nuraeny, Siti. Analisis kualitas mikrobiologis produk usaha kecil menengah (UKM) di kabupaten tegal tahun 2009. Skripsi. Purwokerto: Fakultas Kesehatan Masyarakat Universitas Jendral Sudirman;2009 (Tidak dipublikasikan)

12. Widodo, Yogo. Hubungan tingkat pengetahuan penjamah makanan mengenai hygiene dan sanitasi makanan dengan kualitas bakteriologis makanan pada rumah makan di kota magelang; 2004. (Diakses tanggal 8 Februari 2013). Diunduh dari : http://www.eprints.undip.ac.id

13. Hartono, Budi. Pemantauan kualitas makanan ketoprak dan gado-gado di lingkungan kampus UI depok, melalui pemeriksaan bakteriologis. Jakarta: Seri Kesehatan; 2003 (Tidak dipublikasikan) 